\title{
Overcoming Drug Resistance in Colon Cancer by Aptamer-Mediated Targeted Co-Delivery of Drug and siRNA Using Grapefruit-Derived Nanovectors
}

\author{
Wei Yan ${ }^{a}$ Mingyue Tao ${ }^{b, c}$ Baofei Jiang ${ }^{d}$ Mengchu Yaob,c Yali June Weijie Daia \\ Zhuang Tang ${ }^{a, b}$ Yong Gao ${ }^{b}$ Li Zhang ${ }^{\mathrm{e}}$ Xiaofei Chen ${ }^{\mathrm{b}} \quad$ Qi-long Wang ${ }^{\mathrm{c}, \mathrm{e}}$

\begin{abstract}
aDepartment of Gastroenterology, The Affiliated Huaian No.1 People's Hospital of Nanjing Medical University, Huai'an, bepartment of Clinical Oncology, The Affiliated Huaian No.1 People's Hospital of Nanjing Medical University, Huai'an, 'Huai'an Key Laboratory of Esophageal Cancer Biobank, The Affiliated Huaian No.1 People's Hospital of Nanjing Medical University, Huai'an, ${ }^{\text {dDepartment }}$ of Gastrointestinal Surgery, The Affiliated Huaian No.1 People's Hospital of Nanjing Medical University, Huai'an, eDepartment of Central Laboratory, The Affiliated Huaian No.1 People's Hospital of Nanjing Medical University, Huai'an, China
\end{abstract}

\section{Key Words}

Multidrug resistance $\cdot$ Cancer therapy - Aptamer - Grapefruit-derived nanovectors - Drug delivery

\begin{abstract}
Background/Aims: Multidrug resistance (MDR) is the most common cause of chemotherapy failure. Upregulation of P-glycoprotein (P-gp) is one of the main mechanisms underlying MDR. Methods: In this study, we developed a targeted drug and small interfering (si)RNA codelivery system based on specific aptamer-conjugated grapefruit-derived nanovectors (GNVs) that we tested in MDR LoVo colon cancer cells. The internalization of nanovectors in cancer cells was tested by fluorescence microscopy and flow cytometry. The anti-cancer activity in vitro was determined by colony formation and cell apoptosis assays. The biodistribution of nanovectors was analyzed by live imaging and the anti-cancer activity in vivo was observed. Results: GNVs loaded with aptamer increased doxorubicin (Dox) accumulation in MDR LoVo cells, an effect that was abolished by pretreatment with DNase. The LA1 aptamer effectively promoted nanovector internalization into cells at $4^{\circ} \mathrm{C}$ and increased the targeted delivery of Dox to tumors. Constructs harboring Dox, LA1, and P-gp siRNA more effectively inhibited proliferation and enhanced apoptosis in cultured MDR LoVo cells while exhibiting more potent anti-tumor activity in vivo than free Dox or GNVs loaded with Dox alone or in conjunction with
\end{abstract}

W. Yan, M. Tao and B. Jiang contributed equally to this work.

$\begin{array}{ll}\text { Qi-long Wang, Xiaofei Chen } & \text { Huai'an Key Lab. of Esophageal Cancer Biobank, The Affiliated Huaian No.1 People's Hospital } \\ \text { and Li Zhang } & \text { of Nanjing Medical University, Huai'an, Jiangsu } 223300 \text { (China) } \\ & \text { E-Mail qlwang@njmu.edu.cn; chenxf@njmu.edu.cn; zhangl@njmu.edu.cn }\end{array}$




\section{Cellular Physiology Cell Physiol Biochem 2018;50:79-91 and Biochemistry Published online: 3 October 2018 \begin{tabular}{l|l} 
DOI: 10.1159/000493960 & $\begin{array}{l}\text { C } 2018 \text { The Author(s). Published by S. Karger AG, Basel } \\
\text { www.karger.com/cpb }\end{array}$
\end{tabular}}

Yan et al.: Grapefruit-derived Nanovectors-based Co-Delivery System for Drug

Resistance Reversal

LA1, an effect that was associated with downregulation of P-gp expression. Conclusion: This GNV-based system may be an effective strategy for overcoming MDR in clinical settings.

\section{Introduction}

Multi-drug resistance (MDR) is the major cause of chemotherapy failure. Upregulation of P-glycoprotein (P-gp) expression is one of the main mechanisms underlying MDR [1, 2]. Various strategies have been adopted to overcome MDR in cancer therapy, including monoclonal anti-P-gp antibodies [3], ATP-binding cassette transporter inhibitors [4], or targeted knockdown of gene expression using small interfering (si)RNAs [5]. With advances in nanotechnology, an increasing number nanocarrier-based cancer therapeutics have been developed and are being tested in clinical trials for the treatment of drug-resistant cancers [6-8]. An important benefit of these approaches is that nanocarriers can be internalized by MDR cells via non-specific endocytosis, resulting in higher intracellular accumulation of the drug. To enhance tumor targeting, the nanovector surface is usually modified with a ligand [9] or antibody [10]. Aptamers identified by an in vitro selection procedure known as systematic evolution of ligands by exponential enrichment (SELEX) have broad medical applications as drug delivery ligands due to their low immunogenicity and toxicity, high binding affinity, specificity, and wide range of targets $[11,12]$.

In this study, we established a multifunctional co-delivery system based on grapefruit lipid-derived nanovectors (GNVs), which we previously showed to be capable of delivering many types of therapeutic agents including drugs, siRNAs, and antibody without in vivo toxicity $[13,14]$. We used the single-stranded (ss)DNA aptamer LA1 specific to MDR LoVo human colon cancer cells (LoVo/MDR cells) to design a LA1/P-gp siRNA (Psi)-conjugated nanocarrier that was loaded with the chemotherapy drug doxorubicin (Dox). LA1 enhanced the targeted delivery of the payload to LoVo/MDR cells, inhibiting proliferation and increasing apoptosis in vitro and suppressing LoVo/MDR cell-derived tumor growth in a mouse xenograft model. This is the first demonstration of a three-pronged approach for the treatment of MDR cancer.

\section{Materials and Methods}

\section{Materials}

Dox and branched polyethylenimine (PEI; average molecular weight 25, 000 Da, cat. no. 408727) were purchased from Sigma-Aldrich (St Louis, MO, USA). The near-infrared fluorescein dye DiIC18(7) (1, 1'-dioctadecyl-3, 3,3',3'-tetramethylindotricarbocyanine iodide) (DiR) was purchased from Life Technologies (Carlsbad, CA, USA). F-12K medium, fetal bovine serum (FBS), penicillin, and streptomycin for cell culture were obtained from Thermo Fisher Scientific (Waltham, MA, USA).

\section{Cell culture and mice}

LoVo human colon cancer cells were purchased from American Type Culture Collection (Manassas, VA, USA). LoVo/MDR cells were generated by exposing the cells to increasing concentrations of Dox. LoVo and LoVo/MDR cell lines were maintained in F-12K medium supplemented with FBS (10\%), penicillin (50 IU/ $\mathrm{ml})$, and streptomycin $(50 \mathrm{ng} / \mathrm{ml})$ and cultured in a humidified $\mathrm{CO}_{2}$ incubator at $37^{\circ} \mathrm{C}$.

BALB/c and BALB/c SCID mice (6-8 weeks old) were purchased from the Institute of Comparative Medicine of Yangzhou University (Yangzhou, China). Animal experiments were carried out in accordance with the National Institutes of Health Guide for the Care and Use of Laboratory Animals (Bethesda, MD, USA).

Aptamer selection

The original ssDNA library contained 86-mer oligonucleotides with the sequence 5'-GGATCCTATGACGCATTGACCC-N30-GGCTCGGACTGTTCCCTATAGTGAGTCGTATTAG-3', in which N30 


\section{Cellular Physiology Cell Physiol Biochem 2018;50:79-91 \begin{tabular}{l|l} 
and Biochemistry Published online: 3 October 2018 & $\begin{array}{l}\text { DOI: } 2018 \text { The Author(s). Published by S. Karger AG, Basel } \\
\text { www.karger.com/cpb }\end{array}$
\end{tabular}}

Yan et al.: Grapefruit-derived Nanovectors-based Co-Delivery System for Drug

Resistance Reversal

represents random oligonucleotides based on equal incorporation of $\mathrm{A}, \mathrm{T}, \mathrm{G}$, and $\mathrm{C}$ at each position. The procedure for aptamer selection has been previously reported [15]. Briefly, the original ssDNA library was denatured for $5 \mathrm{~min}$ at $95^{\circ} \mathrm{C}$ and cooled for $10 \mathrm{~min}$ on ice. After incubation with LoVo/MDR cells on ice for $1 \mathrm{~h}$, the supernatant was removed and cells were collected and resuspended in $500 \mu \mathrm{lddH_{2 }} \mathrm{O}$. Cell-bound ssDNA was harvested by heating for $5 \mathrm{~min}$ at $95^{\circ} \mathrm{C}$ and used as template for PCR amplification. Doublestranded (ds)DNA was used as a template for asymmetric PCR, and the ssDNA products were used in the next round of selection. After three rounds of selection, LoVo cells were used as a negative selection target and unbound ssDNA was incubated with LoVo/MDR cells for the next round of selection. To avoid nonspecific binding in vivo, peripheral blood mononuclear cells (PBMCs) from healthy volunteers were used as a counter selection target after the 10 th round of selection.

ssDNAs from the 12th round of selection were amplified; dsDNAs were digested and subcloned into the pUC19 vector, which was used to transform Escherichia coli DH5 $\alpha$ cells. Selected clones were sequenced and the secondary structure was analyzed using DNAMAN v.3.2 software (Lynnon Biosoft, Pointe-Claire, QC, Canada). Identified aptamers were named LA1...LAn.

\section{Flow cytometry}

To determine the binding affinity of selected aptamers, we selected the top three candidates from among 50 clones (LA1-3), with the original ssDNA library serving as a control. Briefly, LoVo or LoVo/MDR cells $\left(5 \times 10^{5}\right)$ were incubated with 6-carboxyfluorescein (FAM)-labeled LA1, LA2, and LA3 (1 nM-150 nM) and the original ssDNA library $(250 \mathrm{nM})$ at $4^{\circ} \mathrm{C}$ for $30 \mathrm{~min}$; the cells were then washed three times with phosphate-buffered saline (PBS) and analyzed by flow cytometry (Accuri C6; BD Biosciences, Franklin Lakes, NJ, USA). Data were analyzed using FlowJo software (TreeStar, Ashland, OR, USA).

To assess binding specificity, LoVo/MDR, MDA-MB-231 human breast cancer, SGC-7901 human gastric cancer, or A549 human pulmonary adenocarcinoma cells or PBMCs from healthy volunteers were incubated with the aptamer with the highest binding affinity (FAM-LA1) for $30 \mathrm{~min}$ at $4^{\circ} \mathrm{C}$. After washing three times, cells were resuspended in PBS and analyzed by flow cytometry. The mean fluorescence intensity of the target cells bound to the aptamer was used to calculate the binding affinity. The equilibrium dissociation constant Kd was measured by fitting the dependence of the fluorescence intensity of specific binding on the concentration of the aptamers to the equation $Y=B \max X /(K \mathrm{~d}+X)$ using GraphPad Prism 5.0.

To examine the uptake of nanovectors with or without loaded LA1 aptamer, GNV-Dox or GNV-Dox-LA1 were incubated with LoVo cells for $6 \mathrm{~h}$ at different temperatures $\left(37^{\circ} \mathrm{C}\right.$ or $\left.4^{\circ} \mathrm{C}\right)$ or in culture medium with different $\mathrm{pH}$ values (7.4 or 5.5). The cells were collected and washed three times with PBS, and Dox-positive cells were detected by flow cytometry.

Preparation and characterization of Dox, LA1, and Psi-loaded GNVS

Free GNVs and GNVs loaded with Dox (GNV-Dox), Dox+LA1 (GNV-Dox-LA1), and Dox+LA1+Psi (GNVDox-Psi-LA1) were prepared as previously reported [16]. Pre-prepared GNV-Dox was incubated with PEI for $60 \mathrm{~min}$ at room temperature; after centrifugation at 36, $000 \mathrm{rpm}$ for $1 \mathrm{~h}$, PEI-modified GNV-Dox (GNV-DoxPEI) were resuspended and incubated overnight at $4^{\circ} \mathrm{C}$ with LA1 without or with Psi. Free LA1 or Psi was removed by ultracentrifugation at 36, $000 \mathrm{rpm}$ for $1 \mathrm{~h}$.

The average size and zeta potential of GNVs, GNV-Dox, GNV-Dox-LA1, and GNV-Dox-Psi-LA1 were analyzed with the ZLS Z3000 particle sizing system (Nicomp International, Orlando, FL, USA). Nanoparticle morphology was observed with a Nova NanoSEM 230 scanning electron microscope (SEM; FEI Tecnai, Hillsboro, OR, USA).

\section{Florescence microscopy}

To determine whether the LA1 aptamer could promote Dox internalized, LoVo/MDR cells were incubated with free Dox, GNV-Dox, and GNV-Dox-LA1 in the wells of a chamber slide at $37^{\circ} \mathrm{C}$ for $6 \mathrm{~h}$. After three washes with PBS, cells were fixed with $2 \%$ paraformaldehyde (PFA) for $10 \mathrm{~min}$ at $22^{\circ} \mathrm{C}$, and Dox accumulation in the cells was detected by fluorescence microscopy (Leica, Wetzlar, Germany).

Western blotting

P-gp expression in LoVo/MDR cells was evaluated by western blotting. Cells ( $5 \times 10^{5} /$ well) were treated with PBS, GNVs, free Dox, GNV-Dox, GNV-Dox-LA1, or GNV-Dox-Psi-LA1 for $36 \mathrm{~h}$, then collected and lysed. 


\section{Cellular Physiology Cell Physiol Biochem 2018;50:79-91

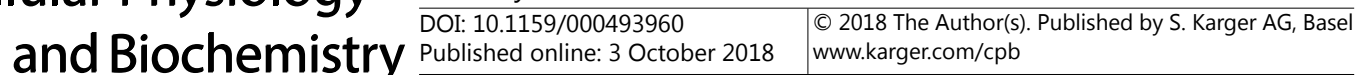 \\ Yan et al.: Grapefruit-derived Nanovectors-based Co-Delivery System for Drug}

Resistance Reversal

Total proteins were separated on a $10 \%$ polyacrylamide gel by sodium dodecyl sulfate-polyacrylamide gel electrophoresis and transferred to a polyvinylidene difluoride membrane that was probed with anti-P-gp or -glyceraldehyde 3-phosphate dehydrogenase (control) antibody. Protein bands were visualized with enhanced chemiluminescence reagent. To visualize P-gp expression in tumor tissues, random biopsies obtained from LoVo cell-derived xenografted tumors were homogenized, lysed, and analyzed by western blotting.

\section{Colony formation assay}

Cell proliferation was evaluated with the colony formation assay. Briefly, 200 LoVo/MDR cells were seeded in each well of 6-well plate with $2 \mathrm{ml}$ complete medium. After $24 \mathrm{~h}$, cells were treated with PBS, GNVs, free Dox, GNV-Dox, GNV-Dox-LA1, or GNV-Dox-Psi-LA1 every 5 days for 10 days. The medium was removed and cell colonies were fixed with $4 \%$ paraformaldehyde for $15 \mathrm{~min}$ and stained with $0.1 \%$ crystal violet in PBS for $30 \mathrm{~min}$. The number of colonies was counted and images were obtained with a GelDoc-It2 imager (Bio-Rad, Hercules, CA, USA).

\section{In vivo imaging and biodistribution analysis}

Mice were subcutaneously inoculated with LoVo/MDR cells $\left(5 \times 10^{6}\right.$ cells per mouse $)$ and then randomly divided into four groups that were intravenously injected with PBS, DiR-GNVs, DiR-GNV-Dox, or DiR-GNV-Dox-LA1. After $24 \mathrm{~h}$, in vivo fluorescence in tumor tissues and major organs (heart, liver, spleen, lung, kidney, brain, and thymus) was imaged with the FX Pro system (Carestream Health, Rochester, NY, USA); signal intensity was quantified using Multiplex software.

To determine the circulation time of nanoparticles, peripheral blood (200 $\mu \mathrm{l})$ was collected from mice at different time points $(24,48,72,96,120$, and $144 \mathrm{~h})$ and DiR signal intensity was measured with the In vivo FX Pro imaging system.

\section{HE staining}

To assess the therapeutic safety, livers and hearts from BALB/c mice treated with PBS or GNV-Dox-LA1 ( $4 \mathrm{mg} / \mathrm{kg}$ Dox, I.V. injection for 1, 3 or 5 times) were fixed overnight in 4\% paraformaldehyde and embedded in paraffin; $5 \mu \mathrm{m}$ sections of tissues were than stained with H\&E.

\section{Assessment of liver damage}

BALB/c mice were treated with PBS or GNV-Dox-LA1 (4 mg/kg Dox, I.V. injection for 1, 3 or 5 times), the sera of mice was collected $24 \mathrm{~h}$ after treatment, the ALT, AST and ALP were quantitatively analyzed using the Clinical Chemistry Analyzer for animals (BS-240 VET, Mindray, China).

\section{LoVo cell-derived xenograft tumors in mice}

$5 \times 10^{6} \mathrm{LoVo} / \mathrm{MDR}$ cells were subcutaneously injected into the right fore flank of each SCID mouse. After reaching a volume to $\sim 100 \mathrm{~mm}^{3}$, LoVo/MDR cell-derived tumor-bearing mice were randomly divided into six groups ( $\mathrm{n}=5 \mathrm{mice} /$ group) and were intravenously injected with PBS, GNVs, free Dox (4 mg/ $\mathrm{kg}$ ), GNV-Dox (4 mg/kg Dox), GNV-Dox-LA1 (4 mg/kg Dox), and GNV-Dox-Psi-LA1 (4 mg/kg Dox; 1 mg/kg Psi) every 5 days for a total of five times. Tumor size and weight were recorded after 30 days and P-gp expression in tumors was analyzed by western blotting.

\section{Statistical analysis}

Data are expressed as mean \pm SD. Differences among groups were compared with the two-tailed Student's t test and by analysis of variance. Differences were considered statistically significant at $p<0.05$.

\section{Results}

Selection of aptamers recognizing LoVo/MDR cells

Cell-SELEX was carried out to obtain aptamers specific to LoVo/MDR cells (Fig. 1A). LoVo/MDR cells with lower drug accumulation (Fig. 1B, C) and higher P-gp expression (Fig. 1D) were maintained in our laboratory for use as target cells. After 12 rounds of selection, the 


\section{Cellular Physiology Cell Physiol Biochem 2018;50:79-91 \\ and Biochemistry Published online: 3 October 2018 \begin{tabular}{l|l} 
DOI: 10.1159/000493960 & $\begin{array}{l}\text { C } 2018 \text { The Author(s). Published by S. Karger AG, Basel } \\
\text { www.karger.com/cpb }\end{array}$
\end{tabular} \\ Yan et al.: Grapefruit-derived Nanovectors-based Co-Delivery System for Drug}

Resistance Reversal

ssDNA pool was amplified, subcloned, and sequenced. The top three aptamers (LA1, 36\%; LA2, 14\%; and LA3, 10\%; Fig. 1E) from among 50 clones were selected while the original ssDNA library served as control aptamer (Fig. 1F). LA1 bound to LoVo/MDR cells with highest affinity (Fig. 2A, B, Kd=39.6 $\pm 5.9 \mathrm{nM}$ ) and best specificity (Fig. 2C, D, Kd=33.6 \pm 4.9 $\mathrm{nM}$ ). To prevent non-specific binding to normal blood cells in vivo, leukocytes from healthy volunteers were incubated with LA1; the results indicated that there was very low cross reactivity (Fig. 2E).

\section{Characterization of nanovectors}

The morphology of GNVs, GNV-Dox, and GNV-Dox-LA1 was observed by scanning electron microscopy. The diameter of the three nanovectors was about $200 \mathrm{~nm}$ (Fig. 3A). Size and surface charge distribution were analyzed by dynamic light scattering; the average sizes were 135.7, 161.2 and $173.4 \mathrm{~nm}$, respectively (Fig. 3B) and average zeta potentials were $-33.3,-30.58$, and $-37.43 \mathrm{mV}$, respectively (Fig. 3C).

\section{Internalization of nanovectors by LoVo/MDR cells}

Dox accumulation in LoVo/MDR cells was evaluated by incubating the cells with free Dox, GNV-Dox, and GNV-Dox-LA1. Cells incubated with GNVs with or without LA1 modification showed greater accumulation of Dox than those incubated with free Dox (Fig. 4A, B). This enhancement of drug uptake in the presence of nanovectors was abolished by pretreatment with DNase (Fig. 4C). Uptake efficiency was temperature-dependent, although temperature had no effect on GNV-Dox-LA1 uptake (Fig. 4D). Internalization of GNV-Dox and GNV-DoxLA1 was unaffected by the $\mathrm{pH}$ of the medium (Fig. 4E).

\section{Biodistribution and therapeutic safety of nanovectors}

The biodistribution of nanovectors modified with LA1, LoVo/MDR cell-derived tumorbearing mice intravenously injected with PBS, DiR-GNVs, DiR-GNV-Dox, or DiR-GNV-Dox-LA1 was evaluated by in vivo imagine. The DiR signal was weakly detected in tumors, whereas a strong signal was observed in the liver and spleen following DiR-GNV or DiR-GNV-Dox injection. In contrast, in mice injected with DiR-GNV-Dox-LA1, DiR fluorescence was much higher in the tumor than the DiR-GNV or DiR-GNV-Dox injected mice (Fig. 5A, B, ${ }^{* * *} p<0.001$ ). Additionally, the circulation time of GNVs or GNV-Dox was markedly reduced by conjugating with LA1 (Fig. 5C).

To further explore the potential in vivo cytotoxic effects of the GNV-Dox-LA1 system, serum levels of alanine aminotransferase (ALT), aspartate aminotransferase (AST) and alkaline phosphatase (ALP) of mice pre-treated with GNV-Dox-LA1 were measured for liver injury. ALT, AST and ALP were not induced due to GNV-Dox-LA1 treatments (Fig. 5D). Histological analysis of tissues from GNV-Dox-LA1 treated animals (Fig. 5E) revealed no pathological changes in the hearts or livers when compared with tissues from untreated mice.

\section{Characterization and analysis of in vitro GNV-Dox-Psi-LA1 cytotoxicity}

For enhanced anti-cancer activity, we developed GNV-Dox-Psi-LA1 (Fig. 6A); with a size distribution of $283.8 \pm 84.7 \mathrm{~nm}$ (Fig. 6B) and high internalization efficacy in LoVo/MDR cells (Fig. 6C). LoVo/MDR cells were incubated with PBS, GNVs, free Dox, GNV-Dox, GNV-Dox-LA1, or GNV-Dox-Psi-LA1; P-gp expression was most effectively inhibited in cells treated with GNV-Dox-Psi-LA1 (Fig. 6D). We also assessed the anti-cancer activity of GNV-Dox-Psi-LA1 in vitro with the colony formation assay and examined apoptosis by Annexin V/propidium iodide staining and flow cytometry. Colony formation by LoVo/MDR cells was attenuated by GNV-Dox, GNV-Dox-LA1, and especially GNV-Dox-Psi-LA1 (Fig. $6 \mathrm{E},{ }^{*} p<0.05$ and ${ }^{* * *} p<0.001$ ). Moreover, the percentage of apoptotic cells was increased from $14.8 \%$ in cells treated with free Dox to $24.3 \%$ in the presence of GNV-Dox (Fig. $6 \mathrm{~F},{ }^{*} p<0.05$ and ${ }^{* *} p<0.01$ ). The proapoptotic effect of GNV-Dox was enhanced by conjugating LA1 (GNV-Dox-LA1, 30\%) or both LA1 and Psi (GNV-Dox-Psi-LA1, 41\%). 


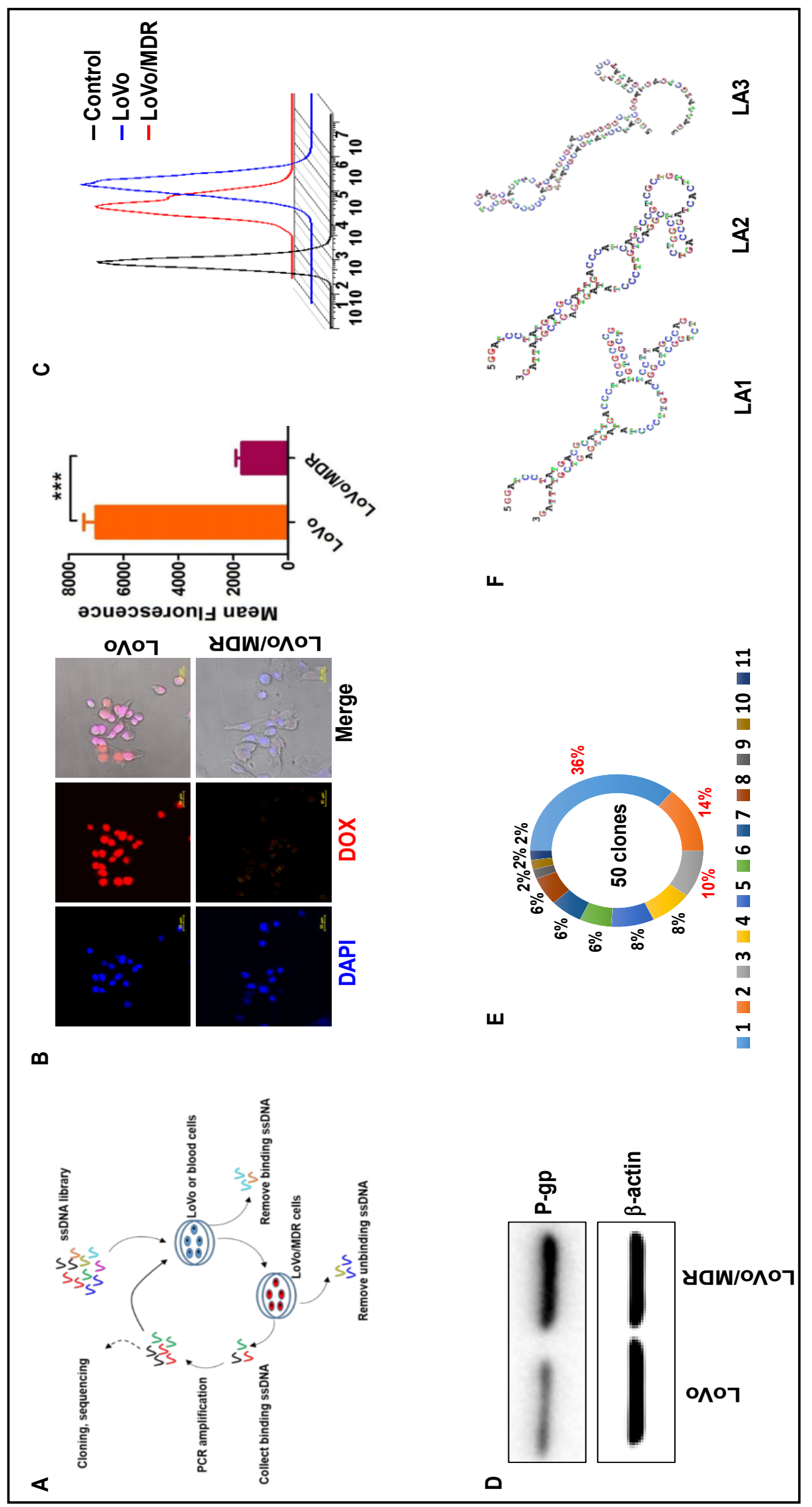

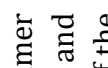

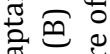

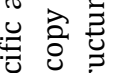

要

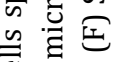

\&

局

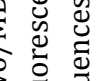

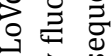

낭 흔

$\stackrel{\square}{0}$

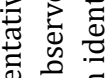

ญे

告

远

焉

䲶 坖

ये जे

ง ํํㅇ

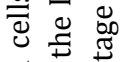

ㅎํำ

政

정

象完

¿

ธั ํำ

纯

ชั

离营

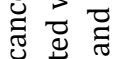

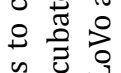

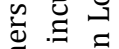

를 


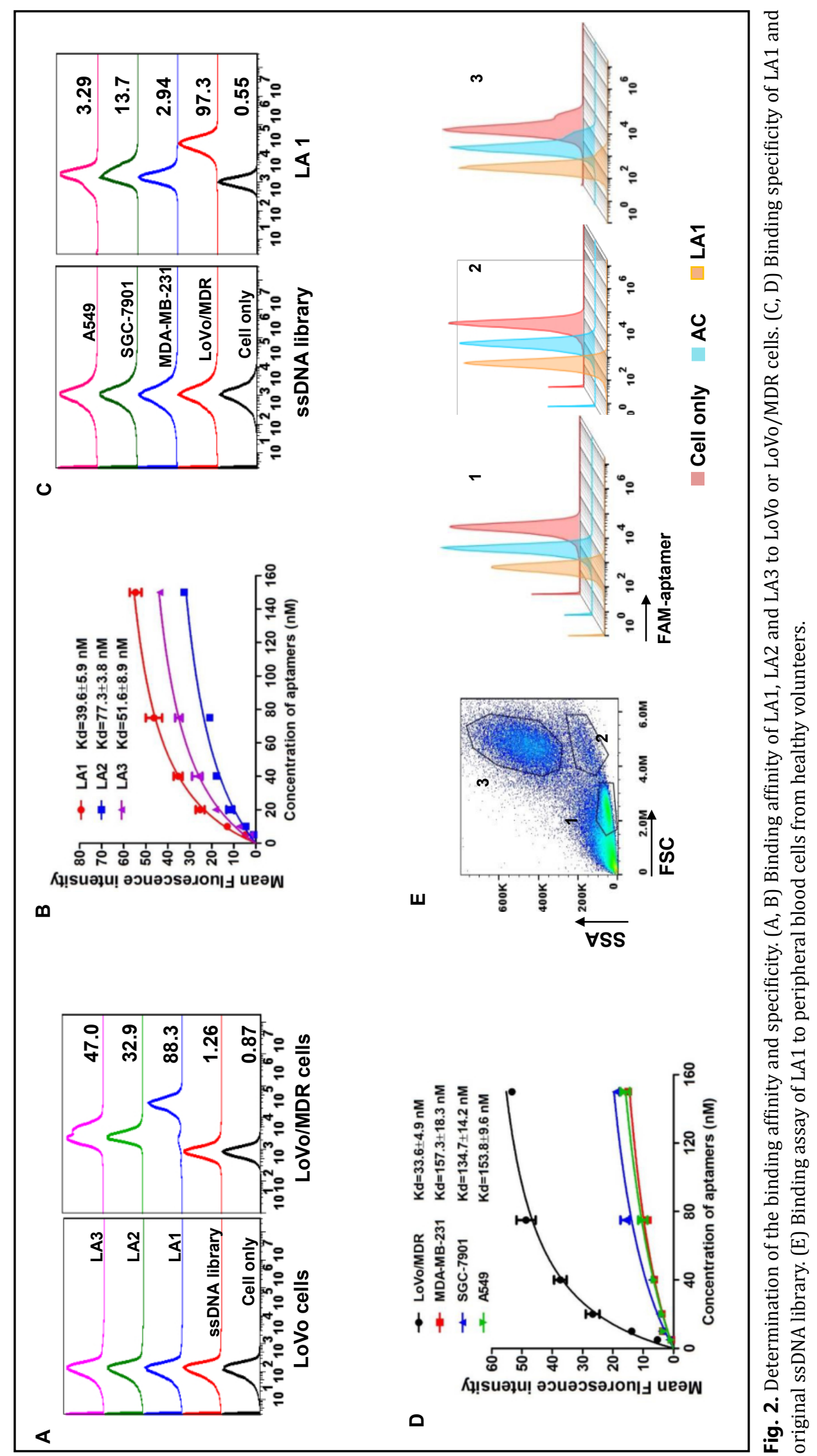




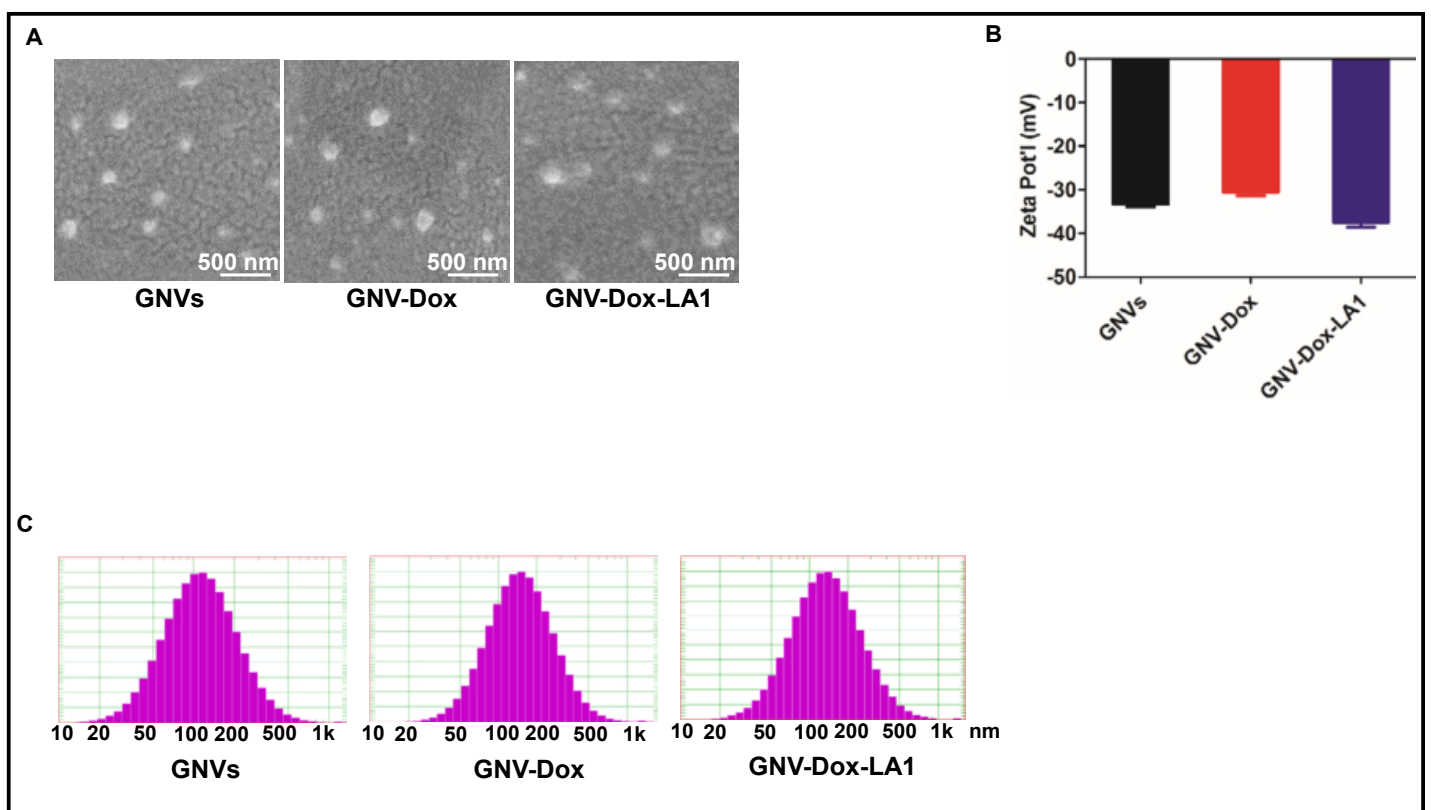

Fig. 3. Characterization of GNVs, GNV-Dox and GNV-Dox-LA1. (A) SEM images of GNVs, GNV-Dox and GNV-Dox-LA1 (insert scale bar, $500 \mathrm{~nm}$ ). (B) Zeta potential of GNVs, GNV-Dox and GNV-Dox-LA1. (C) Size distribution of GNVs, GNV-Dox and GNV-Dox-LA1.

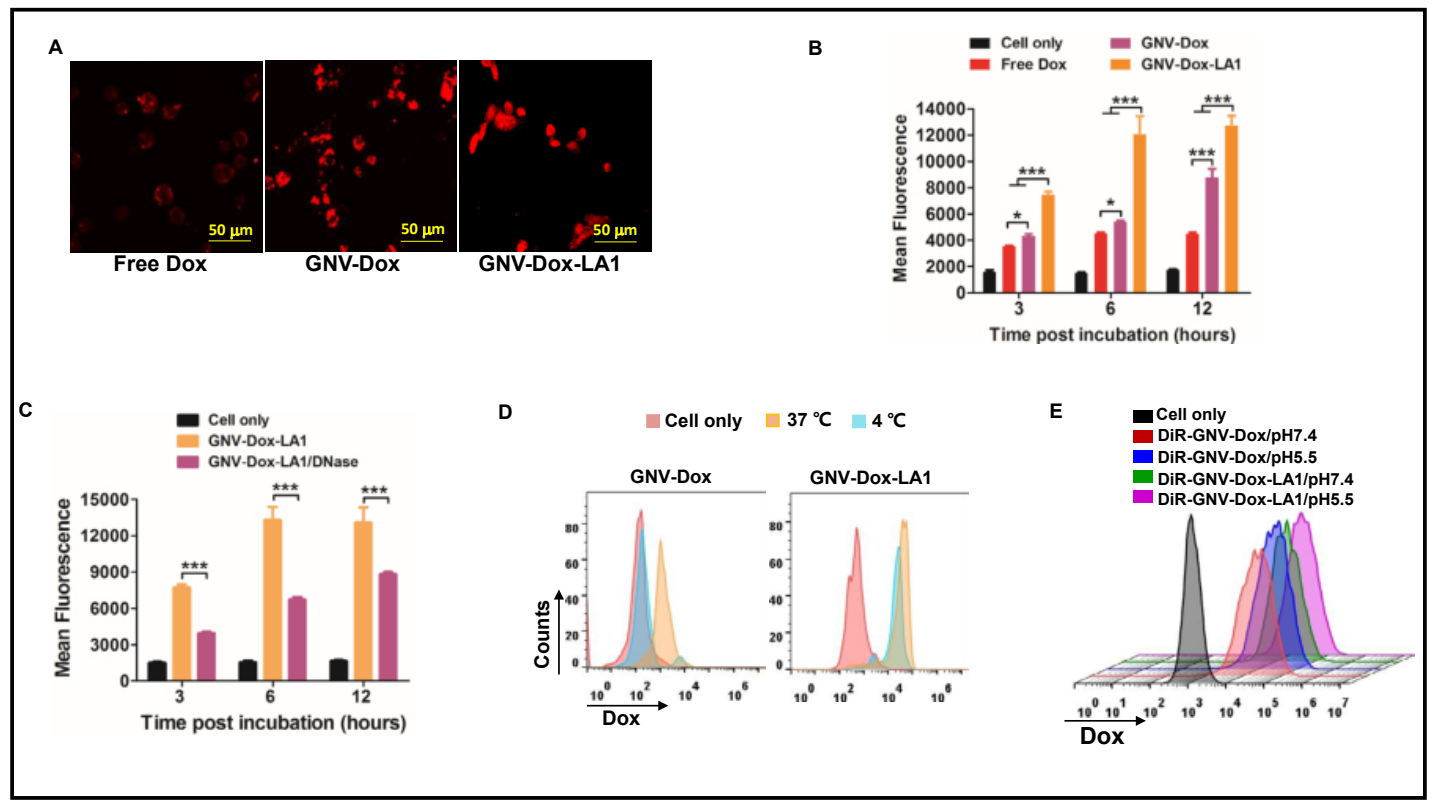

Fig. 4. Internalization of free Dox and co-delivery system in LoVo/MDR cells. (A) Free Dox, GNV-Dox, GNV-Dox-LA1 were respectively incubated with LoVo/MDR cells and the accumulation of Dox in cells was observed by flurescence microscopy. (B) Quantitative analysis of Dox accumulation in LoVo/MDR cells at different time point $(3,6,12 \mathrm{~h})$ by flow cytometry. (C) Effect of DNase on internalization of GNV-DoxLA1 in LoVo/MDR cells. Comparison of the uptake efficacy of GNV-Dox and GNV-Dox-LA1 under different temperature (D) and $\mathrm{pH}$ conditions (E). ${ }^{*} \mathrm{p}<0.05$ and ${ }^{* * *} \mathrm{p}<0.001$. 
Cellular Physiology

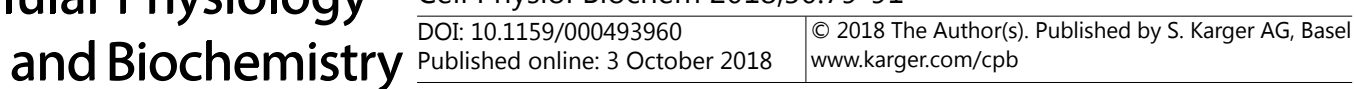
Yan et al.: Grapefruit-derived Nanovectors-based Co-Delivery System for Drug Resistance Reversal

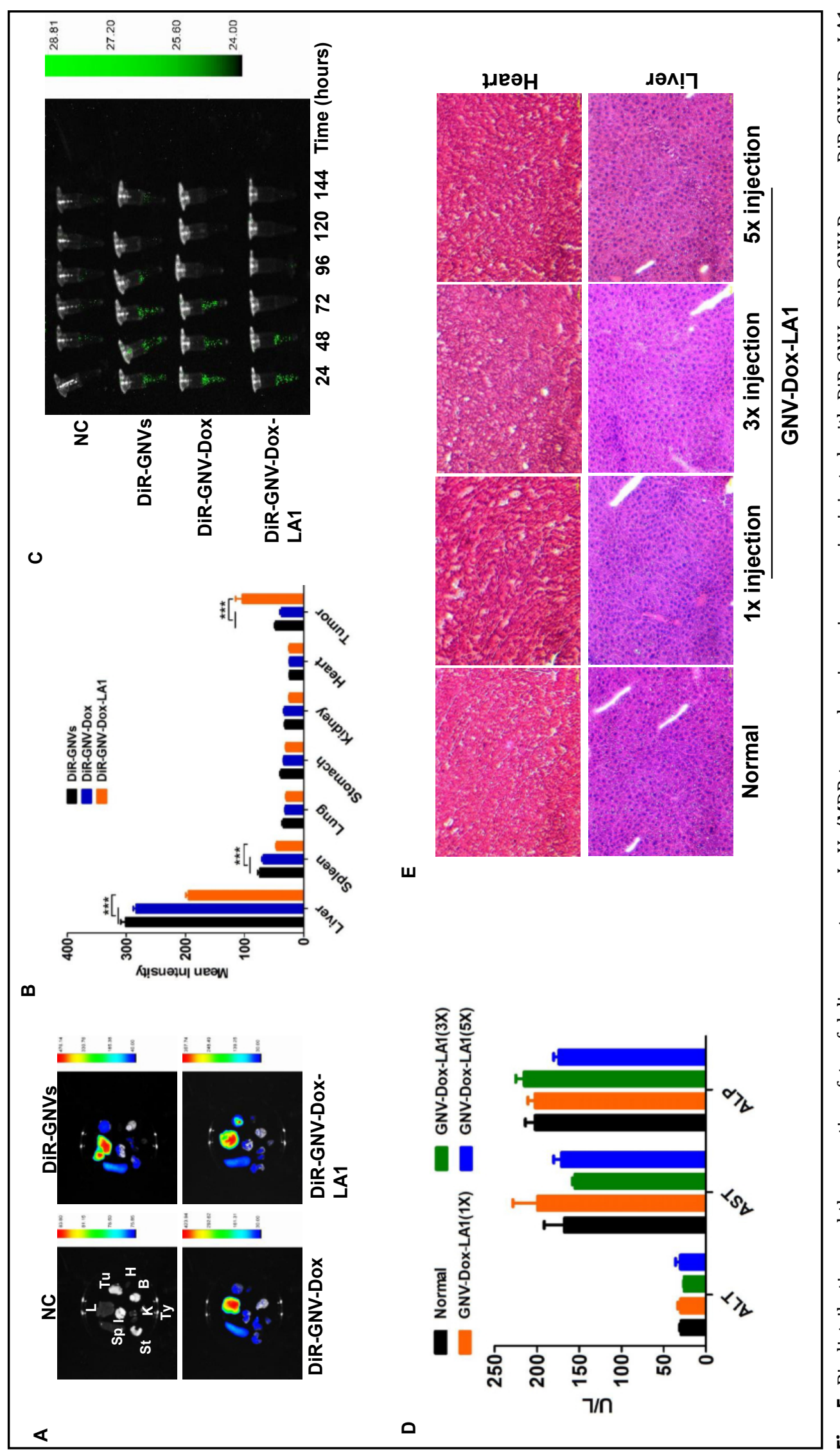

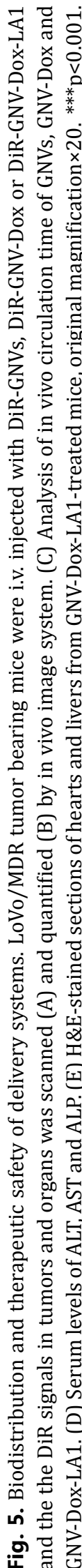



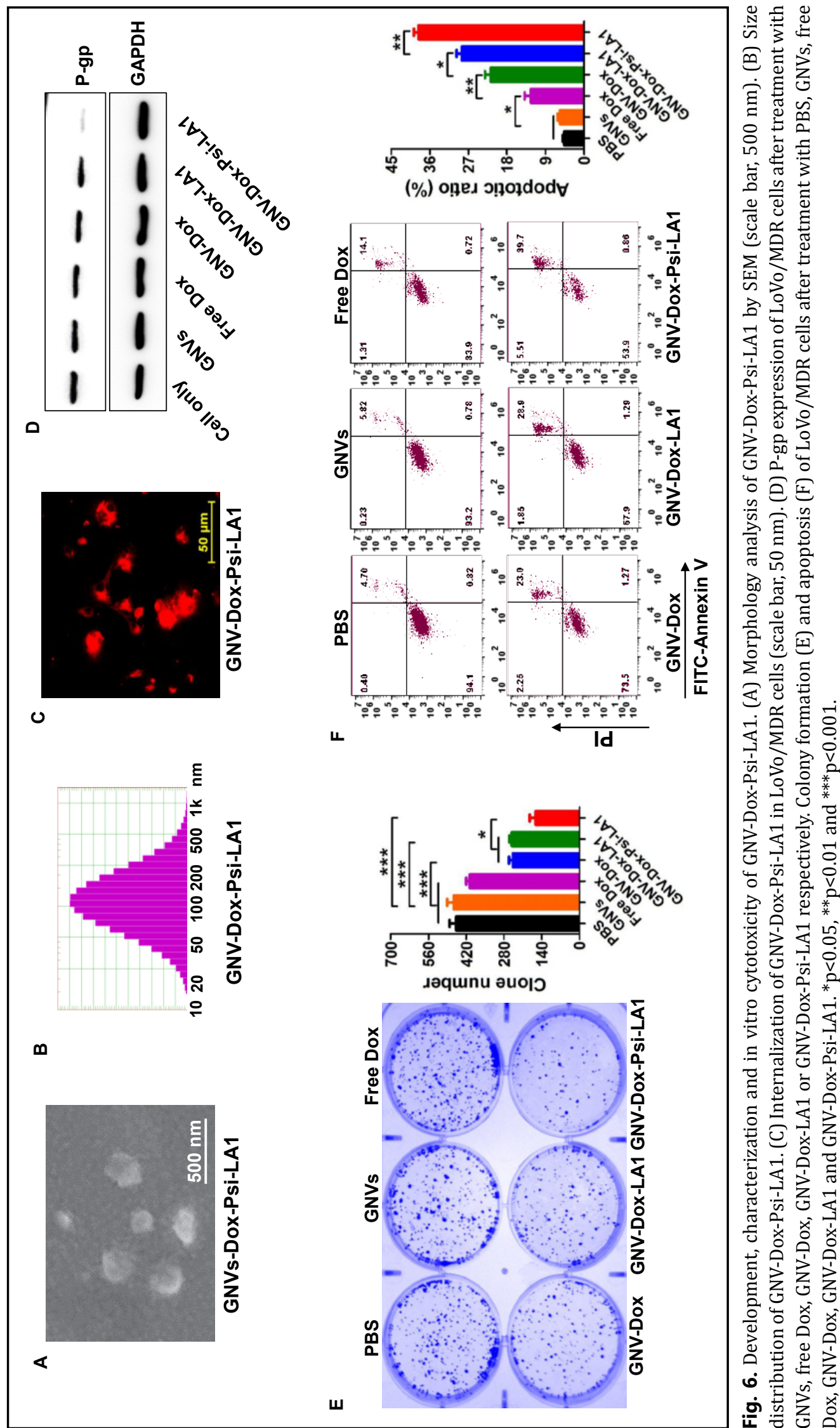


\section{Cellular Physiology Cell Physiol Biochem 2018;50:79-91 and Biochemistry Published online: 3 October 2018 \begin{tabular}{l|l} 
DOI: 10.1159/000493960 & $\begin{array}{l}\text { C } 2018 \text { The Author(s). Published by S. Karger AG, Basel } \\
\text { www.karger.com/cpb }\end{array}$
\end{tabular}}

Yan et al.: Grapefruit-derived Nanovectors-based Co-Delivery System for Drug

Resistance Reversal

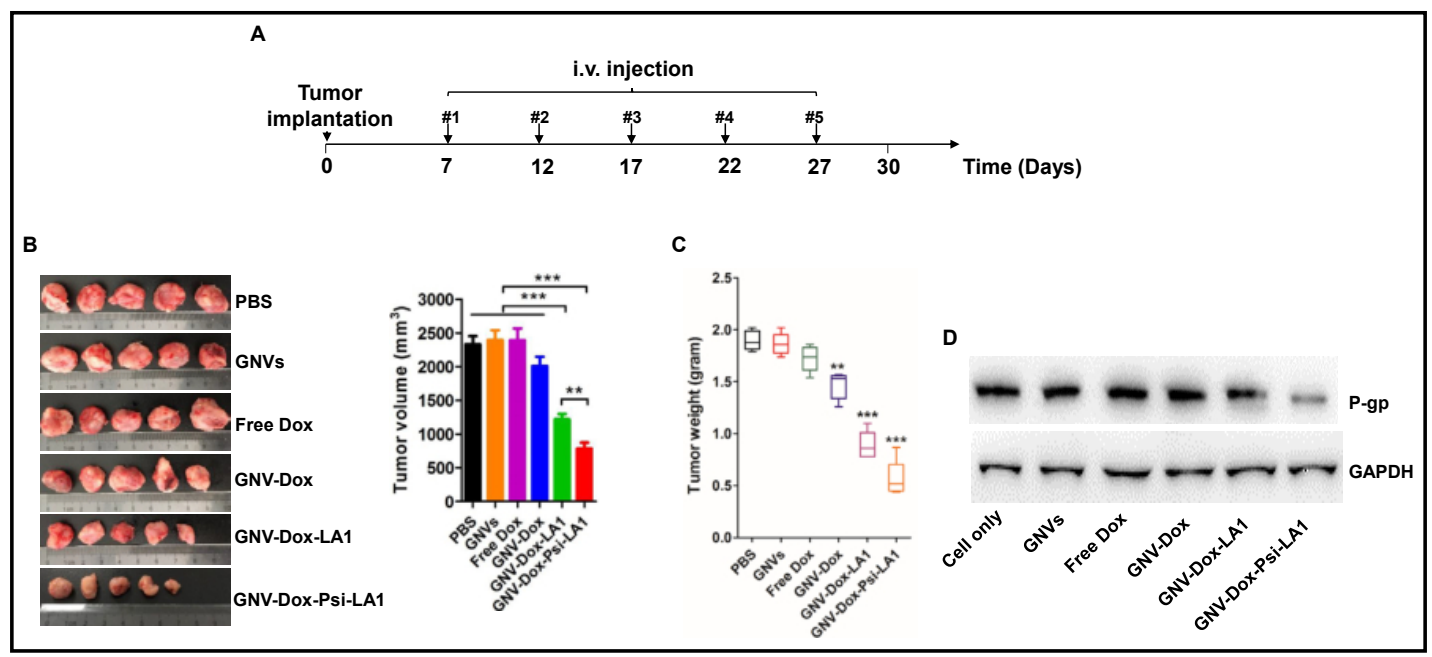

Fig. 7. In vivo anti-LoVo/MDR cancer activity. (A) Protocol for tumor implantation and treatment. (B) Photography of tumor tissues. (C) Tumor weight. (D) Expression of P-gp in tumor tissues. ${ }^{* *}$ p $<0.01$ and $* * * \mathrm{p}<0.001$.

\section{In vivo anti-cancer activity}

To investigate the ability of GNV-Dox-Psi-LA1 to inhibit tumor growth in vivo, LoVo/ MDR cells were implanted into SCID mice. Tumor-bearing mice were then intravenously administered GNVs, Dox, GNV-Dox, GNV-Dox-LA1, or GNV-Dox-Psi-LA1 every 5 days for 30 days (Fig. 7A). GNV-Dox-Psi-LA1 most potently suppressed tumor growth (Fig. 7B, C, ${ }^{* *} p<0.01$ and ${ }^{* * *} p<0.001$ ) and P-gp expression (Fig. 7D) in tumors.

\section{Discussion}

Nanoparticle-based drug delivery has been used extensively to overcome MDR in cancer. The passive targeting of nanomaterials was the principal advantage in earlier studies. On the one hand, drug solubility and stability can be improved and the circulation time can be prolonged by conjugation with nanovectors, which can also induce the selective transport of drugs to tumor sites based on the enhanced permeability and retention effect $[17,18]$. Numerous inorganic $[19,20]$ and organic nanocarriers [21, 22] have been developed for drug delivery, but their potential hazards to human health and the environment have greatly limited their widespread clinical application [23, 24]. In the present study we modified biocompatible GNVs that were previously developed by our group. Unlike engineered nanoparticles, the GNVs - which were assembled from edible grapefruit-derived lipidshad no detectable toxicity in vitro or in vivo [14].

Attaching ligands such as folic acid [25], transferrin [26], engineered antibodies [27], or aptamers [28] to the nanoparticle surface can enhance their biocompatibility, uptake, and retention. Aptamer-nanoparticle conjugates are particularly useful for therapeutic applications due to the ability of aptamers to bind with high affinity to a specific target. We initially developed a GNVs modified with LoVo/MDR cell-specific ssDNA aptamers and loaded with Dox (GNVs-Dox-LA1). The presence of LA1 significantly increased Dox internalization in LoVo/MDR cells; the fact that DNase pre-treatment abolished this effect confirmed the role of LA1 in this process. In addition, in contrast to our previous study, we found here that ambient temperature had no effect on GNV-Dox-LA1 uptake by LoVo/MDR cells, indicating that aptamer/target cell binding is ATP independent. Additionally, Dox delivery to LoVo/ MDR tumor tissues was increased by modification of GNV-Dox with LA1, consistent with findings reported by others $[29,30]$. 


\section{Cellular Physiology Cell Physiol Biochem 2018;50:79-91 \begin{tabular}{l|l|l|} 
and BOI: 10.1159/000493960 & $\begin{array}{l}\text { C) 2018 The Author(s). Published by S. Karger AG, Basel } \\
\text { www.karger.com/cpb }\end{array}$
\end{tabular} \\ Yan et al.: Grapefruit-derived Nanovectors-based Co-Delivery System for Drug}

Resistance Reversal

Although passive or active tumor targeting mediated by GNVs or LA1 can alleviate tumor growth to some extent, it cannot completely reverse MDR. To this end, silencing MDR-associated genes by RNA interference has been investigated as a therapeutic strategy. However, the short half-life and low selectivity of siRNAs has limited their clinical application in humans. Encapsulating siRNAs within inorganic or organic nanoparticles that protect them from RNase degradation can prolong circulation time and increase target tissue specificity [31]. We therefore developed a GNV-based delivery system that included Dox, Psi, and LA1 and found that GNVs-Dox-Psi-LA1 had potent anti-tumor activity both in vitro and in vivo. This system has the advantages of low toxicity, targeted delivery, and co-delivery of both chemotherapeutic drugs and siRNA against MDR-related genes. Our results demonstrate that this GNV-based system may be an effective tool for overcoming MDR cancer in clinical settings.

\section{Acknowledgements}

This work was supported by the National Natural Science Foundation of China (81572977, 81772585, 81800149), Natural Science Foundation of Jiangsu Province (BK20150421, BK20170455), Huai'an Key Laboratory of Esophageal Cancer Biobank Project (HAP201605) and 533 Talents Project of Huai'an (HAA201745).

\section{Disclosure Statement}

The authors have declared that no competing interests exist.

\section{References}

-1 Ferreira RJ, dos Santos DJ, Ferreira MJ: P-glycoprotein and membrane roles in multidrug resistance. Future Med Chem 2015;7:929-946.

-2 Silva R, Vilas-Boas V, Carmo H, Dinis-Oliveira RJ, Carvalho F, de Lourdes Bastos M, Remiao F: Modulation of P-glycoprotein efflux pump: induction and activation as a therapeutic strategy. Pharmacol Ther 2015;149:1-123.

3 Gao Y, Xiong D, Yang M, Liu H, Peng H, Shao X, Xu Y, Xu C, Fan D, Qin L, Yang C, Zhu Z: Efficient inhibition of multidrug-resistant human tumors with a recombinant bispecific anti-P-glycoprotein $\mathrm{x}$ anti-CD3 diabody. Leukemia 2004;18:513-520.

-4 Cui H, Zhang AJ, Chen M, Liu JJ: ABC Transporter Inhibitors in Reversing Multidrug Resistance to Chemotherapy. Curr Drug Targets 2015;16:1356-1371.

5 Talekar M, Ouyang Q, Goldberg MS, Amiji MM: Cosilencing of PKM-2 and MDR-1 Sensitizes MultidrugResistant Ovarian Cancer Cells to Paclitaxel in a Murine Model of Ovarian Cancer. Mol Cancer Ther 2015;14:1521-1531.

6 Qiu L, Chen T, Ocsoy I, Yasun E, Wu C, Zhu G, You M, Han D, Jiang J, Yu R, Tan W: A cell-targeted, sizephotocontrollable, nuclear-uptake nanodrug delivery system for drug-resistant cancer therapy. Nano Lett 2015;15:457-463.

7 Kovacs D, Szoke K, Igaz N, Spengler G, Molnar J, Toth T, Madarasz D, Razga Z, Konya Z, Boros IM, Kiricsi M: Silver nanoparticles modulate $\mathrm{ABC}$ transporter activity and enhance chemotherapy in multidrug resistant cancer. Nanomedicine 2016;12:601-610.

-8 Yin J, Lang T, Cun D, Zheng Z, Huang Y, Yin Q Yu H, Li Y: pH-Sensitive Nano-Complexes Overcome Drug Resistance and Inhibit Metastasis of Breast Cancer by Silencing Akt Expression. Theranostics 2017;7:42044216.

9 He J, Duan S, Yu X, Qian Z, Zhou S, Zhang Z, Huang X, Huang Y, Su J, Lai C, Meng J, Zhou N, Lu X, Zhao Y: Folate-modified Chitosan Nanoparticles Containing the IP-10 Gene Enhance Melanoma-specific Cytotoxic CD8(+)CD28(+) T Lymphocyte Responses. Theranostics 2016;6:752-761. 


\section{Cellular Physiology Cell Physiol Biochem 2018;50:79-91

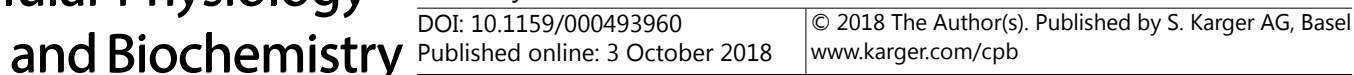

Yan et al.: Grapefruit-derived Nanovectors-based Co-Delivery System for Drug

Resistance Reversal

10 Alibakhshi A, Abarghooi Kahaki F, Ahangarzadeh S, Yaghoobi H, Yarian F, Arezumand R, Ranjbari J, Mokhtarzadeh A, de la Guardia M: Targeted cancer therapy through antibody fragments-decorated nanomedicines. J Control Release 2017;268:323-334.

11 Zhou G, Latchoumanin 0, Bagdesar M, Hebbard L, Duan W, Liddle C, George J, Qiao L: Aptamer-Based Therapeutic Approaches to Target Cancer Stem Cells. Theranostics 2017;7:3948-3961.

12 Li F, Mei H, Gao Y, Xie X, Nie H, Li T, Zhang H, Jia L: Co-delivery of oxygen and erlotinib by aptamer-modified liposomal complexes to reverse hypoxia-induced drug resistance in lung cancer. Biomaterials 2017;145:5671.

-13 Wang Q, Ren Y, Mu J, Egilmez NK, Zhuang X, Deng Z, Zhang L, Yan J, Miller D, Zhang HG: GrapefruitDerived Nanovectors Use an Activated Leukocyte Trafficking Pathway to Deliver Therapeutic Agents to Inflammatory Tumor Sites. Cancer Res 2015;75:2520-2529.

14 Wang Q, Zhuang X, Mu J, Deng ZB, Jiang H, Zhang L, Xiang X, Wang B, Yan J, Miller D, Zhang HG: Delivery of therapeutic agents by nanoparticles made of grapefruit-derived lipids. Nat Commun 2013;4:1867.

15 Sefah K, Shangguan D, Xiong X, O’Donoghue MB, Tan W: Development of DNA aptamers using Cell-SELEX. Nat Protoc 2010;5:1169-1185.

16 Teng Y, Mu J, Hu X, Samykutty A, Zhuang X, Deng Z, Zhang L, Cao P, Yan J, Miller D, Zhang HG: Grapefruitderived nanovectors deliver miR-18a for treatment of liver metastasis of colon cancer by induction of M1 macrophages. Oncotarget 2016;7:25683-25697.

-17 Nakamura H, Fang J, Maeda H: Development of next-generation macromolecular drugs based on the EPR effect: challenges and pitfalls. Expert Opin Drug Deliv 2015;12:53-64.

18 Cerqueira BB, Lasham A, Shelling AN, Al-Kassas R: Nanoparticle therapeutics: Technologies and methods for overcoming cancer. Eur J Pharm Biopharm 2015;97:140-151.

19 Park H, Tsutsumi H, Mihara H: Cell-selective intracellular drug delivery using doxorubicin and alpha-helical peptides conjugated to gold nanoparticles. Biomaterials 2014;35:3480-3487.

20 Chen F, Goel S, Valdovinos HF, Luo H, Hernandez R, Barnhart TE, Cai W: In vivo Integrity and Biological Fate of Chelator-Free Zirconium-89-Labeled Mesoporous Silica Nanoparticles. ACS Nano 2015;9:7950-7959.

-21 Fornaguera C, Dols-Perez A, Caldero G, Garcia-Celma MJ, Camarasa J, Solans C: PLGA nanoparticles prepared by nano-emulsion templating using low-energy methods as efficient nanocarriers for drug delivery across the blood-brain barrier. J Control Release 2015;211:134-143.

22 Bai Y, Xing H, Wu P, Feng X, Hwang K, Lee JM, Phang XY, Lu Y, Zimmerman SC: Chemical Control over Cellular Uptake of Organic Nanoparticles by Fine Tuning Surface Functional Groups. ACS Nano 2015;9:1022710236.

23 Yamashita K, Yoshioka Y, Higashisaka K, Mimura K, Morishita Y, Nozaki M, Yoshida T, Ogura T, Nabeshi H, Nagano K, Abe Y, Kamada H, Monobe Y, Imazawa T, Aoshima H, Shishido K, Kawai Y, Mayumi T, Tsunoda $\mathrm{S}$, Itoh N, et al.: Silica and titanium dioxide nanoparticles cause pregnancy complications in mice. Nat Nanotechnol 2011;6:321-328.

24 Maurer-Jones MA, Gunsolus IL, Murphy CJ, Haynes CL: Toxicity of engineered nanoparticles in the environment. Anal Chem 2013;85:3036-3049.

-25 Wang M, Hu H, Sun Y, Qiu L, Zhang J, Guan G, Zhao X, Qiao M, Cheng L, Cheng L, Chen D: A pH-sensitive gene delivery system based on folic acid-PEG-chitosan - PAMAM-plasmid DNA complexes for cancer cell targeting. Biomaterials 2013;34:10120-10132.

-26 Somani S, Blatchford DR, Millington 0, Stevenson ML, Dufes C: Transferrin-bearing polypropylenimine dendrimer for targeted gene delivery to the brain. J Control Release 2014;188:78-86.

-27 Karra N, Nassar T, Ripin AN, Schwob O, Borlak J, Benita S: Antibody conjugated PLGA nanoparticles for targeted delivery of paclitaxel palmitate: efficacy and biofate in a lung cancer mouse model. Small 2013;9:4221-4236.

28 Wengerter BC, Katakowski JA, Rosenberg JM, Park CG, Almo SC, Palliser D, Levy M: Aptamer-targeted antigen delivery. Mol Ther 2014;22:1375-1387.

29 Xu W, Siddiqui IA, Nihal M, Pilla S, Rosenthal K, Mukhtar H, Gong S: Aptamer-conjugated and doxorubicinloaded unimolecular micelles for targeted therapy of prostate cancer. Biomaterials 2013;34:5244-5253.

30 Baek SE, Lee KH, Park YS, Oh DK, Oh S, Kim KS, Kim DE: RNA aptamer-conjugated liposome as an efficient anticancer drug delivery vehicle targeting cancer cells in vivo. J Control Release 2014;196:234-242.

-31 Aliabadi HM, Landry B, Sun C, Tang T, Uludag H: Supramolecular assemblies in functional siRNA delivery: where do we stand? Biomaterials 2012;33:2546-2569. 